\title{
Peran Kepala Sekolah Dalam Meningkatkan Mutu Sarana Pembelajaran Di SMP
}

\author{
Muhammad Zaenul Mujahidin' ${ }^{1)}$, Wildan' ${ }^{2)}$, Sudirman $^{3)}$ \\ ${ }_{1,2,3}$ Magister Administrasi Pendidikan \\ email: mzaenulmujahidin37@gmail.com
}

\begin{abstract}
Learning facilities are one of the important and main resources in supporting the learning process in schools, for this reason it is necessary to improve the use and management of them, so that the expected goals can be achieved. The purpose of this study is to describe the role of the principal in improving the quality of learning facilities in the Islamic Middle School Al Mujahidin Tempos. This study uses a qualitative approach with descriptive methods that re-draw data that has been collected about the principal's strategy in improving teacher quality. Data collection uses observation sheets, interviews, and documentation studies. Data analysis techniques used three activities, namely data reduction, data presentation and conclusion drawing. The results obtained by improving the quality of learning facilities at Al Mujahidin Islamic Middle School are good for the following reasons: (a) adequate learning facilities with a number of learning facilities in the form of LCD Projectors, Science Laboratories and Computer Laboratories; (b) The approach taken by the principal, teachers do not feel reluctant to submit suggestions and talk directly with the principal about the needs in the learning process; (c) The headmaster directly involved in controlling the construction of school infrastructure together with the deputy headmaster along with the coordinator in the field of facilities and infrastructure. In conclusion, the role of the headmaster in improving the quality and learning facilities has been well implemented in $\mathrm{Al}$ Mujahidin Islamic Middle School.
\end{abstract}

\section{Keywords: The Role of the Principal, Quality of Learning Facilities, Descriptive}

Abstrak: Sarana pembelajaran merupakan salah satu sumber daya yang penting dan utama dalam menunjang proses pembelajaran di sekolah, untuk itu perlu dilakukan peningkatan dalam penggunaan dan pengelolaannya, agar tujuan yang diharapkan dapat tercapai. Tujuan penelitian ini adalah untuk mendeskripsikan peran kepala sekolah dalam meningkatkan mutu sarana pembelajaran di SMP Islam Al Mujahidin Tempos. Penelitian ini menggunakan pendekatan kualitatif dengan metode deskriptif yang menggambarkan kembali data-data yang telah terkumpul mengenai strategi kepala sekolah dalam meningkatkan mutu guru. Pengumpulan data menggunakan lembar observasi, wawancara, dan studi dokumentasi. Teknik analisis data menggunakan tiga alur kegiatan yaitu reduksi data, penyajian data dan penarikan kesimpulan. Hasil penelitian diperoleh peningkatan mutu sarana pembelajaran SMP Islam Al Mujahidin adalah baik dengan alasan sebagai berikut: (a) sarana pembelajaran memadai dengan beberapa fasilitas pembelajaran berupa LCD Proyektor, Laboraturium IPA dan Laboraturium Komputer; (b) Pendekatan yang di lakukan oleh kepala sekolah, guru tidak merasa segan untuk menyampaikan saran dan berbicara langsung dengan kepala sekolah mengenai kebutuhan dalam proses pembelajaran; (c) Kepala sekolah terjun langsung dalam pengontrolan pembangunan prasarana sekolah bersama dengan wakil kepala sekolah beserta koordinator bidang sarana dan prasarana. Kesimpulannya, peran kepala sekolah dalam meningkatkan mutu dan sarana pembelajaran sudah terlaksana dengan baik di SMP Islam Al Mujahidin

Kata Kunci: Peran Kepala Sekolah, Mutu Sarana Pembelajaran, Deskriptif. 


\section{PENDAHULUAN}

Pendidikan merupakan salah satu kebutuhan yang mendapat prioritas utama dalam kehidupan manusia. Pendidikan menjadi salah satu jalan atau cara mengantarkan manusia untuk mencapai tujuan hidupnya, bahkan menjadi suatu kewajiban yang harus dijalani manusia dalam kehidupannya (Pettifor et al, 2008). Keberhasilan program pendidikan melalui proses belajar mengajar sangat dipengaruhi oleh banyak faktor, salah satu di antaranya adalah tersedianya sarana pendidikan yang memadai disertai pemanfaatan dan pengelolaan secara optimal (Hadisaputra et al, 2019). Sarana pendidikan merupakan salah satu sumber daya yang penting dan utama dalam menunjang proses pembelajaran di sekolah (Yustiqvar et al, 2019). Untuk itu perlu dilakukan peningkatan dalam pendayagunaan dan pengelolaannya, agar tujuan yang diharapkan dapat tercapai. Menurut Mulyasa (2004) Sarana pembelajaran adalah peralatan dan perlengkapan yang secara langsung dipergunakan dan menunjang proses pendidikan, khususnya proses belajar mengajar seperti meja kursi,serta alat-alat dan media pembelajaran yang secara langsung digunakan dalam proses pendidikan di sekolah.

Kualitas pengelolaan sarana sebagai komponen yang sangat menunjang tercapainya tujuan pembelajaran pada khususnya dan tujuan pendidikan pada umumnya membuat pengelolaan sarana pendidikan di sekolah menjadi sangat penting agar kelancaran proses belajar mengajar karena tidak terhalang dengan minimnya ketetersediaan sarana yang diperlukan oleh guru dan peserta didik (Afework \& Asfaw, 2014). Menurut Sallis (2002) mutu adalah sebuah filsosofis dan metodologis yang membantu institusi untuk merencanakan perubahan dan mengatur agenda dalam menghadapi tekanan-tekanan eksternal yang berlebihan. Selain itu Prawirosentono (2007) mengartikan mutu suatu produk adalah "Keadaan fisik, fungsi, dan sifat suatu produk bersangkutan yang dapat memenuhi selera dan kebutuhan konsumen dengan memuaskan sesuai nilai uang yang telah dikeluarkan.
Ketersedian sarana untuk menunjang pembelajaran itu terkadang bukan karena kurangnya dana, namun karena kesalahan manajemen. Kemampuan untuk mengelola sarana merupakan hal yang sangat penting karena kualitas pendidikan pada umumnya dan kualitas pembelajaran. Kepala sekolah sangat berperan aktif dalam mengelola sarana secara efektif dan efisien. Kepala sekolah sebagai leader yang memegang maju dan mundurnya suatu sekolah harus dapat mengambil langkah dalam meningkatkan mutu pendidikan (Juliantoro, 2017). Manajemen peningkatan mutu sekolah merupakan salah satu wujud dari reformasi pendidikan. Sistemnya adalah untuk menyediakan pendidikan yang lebih baik dan memadai bagi para peserta didik.

Salah satu permasalahan pendidikan yang dihadapi bangsa Indonesia, yaitu masih rendahnya kualitas pendidikan pada setiap jenjang (Ningrum \& Sobri, 2015). Rendahnya kualitas pendidikan disetiap sekolah salah satunya dipengaruhi oleh kepemimpinan kepala sekolah. Banyak faktor penghambat tercapainya kualitas kepemimpinan seorang kepala sekolah seperti proses pengangkatannya tidak transparan, rendahnya mental kepala sekolah yang ditandai dengan kurangnya motivasi dan semangat serta kurangnya disiplin dalam melakukan tugas dan seringnya datang terlambat, wawasan kepala sekolah yang masih sempit serta banyak faktor lain yang menghambat kinerja seorang kepala sekolah untuk meningkatkan kualitas pendidikan pada lembaga yang dipimpinnya (Fitrah, 2017). Hal ini mengimplikasikan rendahnya produktivitas kerja kepala sekolah yang berimplikasi juga pada mutu. Senada dengan hasil penelitian Muflihah \& Haqiqi (2019) salah satu kendala dalam meningkatkan mutu pendidikan adalah kepala sekolah yang kurang tepat waktu dalam melaksanakan program peningkatan mutu. Adapun peran kepala sekolah dalam meningkatkan mutu pendidikan, yang meliputi perannnya yakni sebagai edukator, manajer, administrator, supervisor, leader, inovator, serta motivator (Mulyasa, 2003; Bachri, 2016). 
Menurut Purwanto (2006) kepemimpinan kepala sekolah sebagai administrator pendidikan bertanggung jawab terhadap kelancaran pelaksanaan pendidikan dan pengajaran di sekolahnya, sehingga penyelenggaraan kegiatan pendidikan dalam mengelola, menilai, membimbing, mengawasi dan mengembangkan pendidikan tersebut dapat terlaksana dengan lebih baik. Kepala sekolah adalah ujung tombak yang dipandang memiliki fungsi mengoptimalkan, mendayagunakan sumber daya yang tersedia secara produktif untuk mencapai tujuan yang ditetapkan bagi unit kerjanya. Kepala sekolah sebagai pemimpin bertanggung jawab menciptakan lingkungan belajar yang kondusif yang memungkinkan anggota sekolah mendayagunakan dan mengembangkan potensinya secara optimal (Uline, \& Tschannen-Moran, 2008). Keberhasilan kepala sekolah dalam melaksanakan tugasnya dapat dilihat dari bentuk kepemimpinan kepala sekolahnya. Wahjosumidjo (2002) mengartikan bahwa: "Kepala sekolah adalah seorang tenaga fungsional guru yang diberi tugas untuk memimpin suatu sekolah dimana diselenggarakan proses belajar mengajar, atau tempat dimana terjadi interaksi antara guru yang memberi pelajaran dan murid yang menerima pelajaran". Sementara Rahman et al (2006) mengungkapkan bahwa "Kepala sekolah adalah seorang guru (jabatan fungsional) yang diangkat untuk menduduki jabatan struktural (kepala sekolah) di sekolah".

Berdasarkan hasil studi lapangan dengan kepala sekolah, wakil kepala dan guru SMP Islam Al Mujahidin, informasi yang didapatkan bahwa kepala dikatakan cukup baik dalam kepemimpinannya, hal ini dibuktikan dengan SMP Islam Al Mujahidin Tempos walaupun terbilang baru, namun perkembangannya cukup baik. Selanjutnya jumlah peserta didik dari tahun ketahun semakin bertambah. Dilihat dari fisik/bangunan Sekolah semakin berkembang baik sarana maupun prasarananya, selain itu kepala sekolah sering mengadakan kumpulan para guru setiap dua minggu sekali untuk membahas permasalahan yang bersangkutan dengan Sekolah.

Sarana pembelajaran tersebut dari informasi kepala sekolah bersifat swadaya yang dilakukan oleh kepala sekolah bersama yayasannya berusaha untuk melengkapi sarana pempelajaran untuk siswa agar dapat mengikuti pembelajaran dengan baik. Kepala Sekolah SMP Islam Al Mujahidin terus menerus berupaya meningkatkan mutu sarana pembelajaran. Hal tersebut diwujudkan dengan terus berusaha melengkapi sarana pembelajaran disekolah. Contoh adanya berbagai macam jenis buku yang dapat menunjang prestasi siswa seperti buku pelajaran wajib, kamus, dan buku tambahan seperti majalah tentang pendidikan ataupun buku cerita tentang pendidikan. Adanya atlas 3 buah, globe 5 buah, komputer yang berjumlah 25 unit, serta alat-alat praktik IPA seperti rangka tubuh manusia,alat ukur, kit listrik, kit magnet, kit optic dan masih banyak lagi yang lainnya. Hal ini mengindikasikan bahwa kepala Sekolah SMP Islam Al Mujahidin telah merencanakan dan melaksanakan peningkatan sarana pembelajaran.

Berdasarkan uraian tersebut, peneliti sangat tertarik untuk melakukan penelitian di SMP Islam Al Mujahidin Tempos tentang Peran kepala sekolah dalam meningkatkan mutu sarana Pendidikan di SMP Islam Al Mujahidin Tempos Gerung Lombok Barat.

\section{METODE PENELITIAN}

Metode penelitian menjelaskan rancangan kegiatan, ruang lingkup atau objek, bahan dan alat utama, tempat, teknik pengumpulan data, definisi operasional variabel penelitian, dan teknik analisis. [Times New Roman, 12, normal].

Penelitian ini menggunakan metode deskriptif dengan pendekatan kualitatif (Arikunto, 2013). Metode deskriptif menggambarkan kembali data-data yang telah terkumpul mengenai peran kepala sekolah dalam meningkatkan mutu sarana pembelajaran. Penelitian deskriptif kualitatif data yang dikumpulkan bukan berupa angkaangka melainkan data tersebut berasal dari naskah wawancara, catatan lapangan dokumen pribadi, catatan memo, dan dokumen resmi 
lainnya (Creswell, 2015). Penelitian kualitatif disebut juga penelitian dengan pendekatan naturalistik, karena situasi lapangan penelitian bersifat natural, wajar, apa adanya, tanpa di manipulasi dan diatur dengan eksperimen atau test (Sugiyono, 2013).

Metode pendekatan yang dilakukan adalah studi kasus eksplanatoris, peneliti ingin mengetahui sebab akibat dari objek yang diteliti, yakni peran kepala sekolah dalam meningkatkan mutu pembelajaran di SMP Islam Al Mujahidin Tempos Gerung Lombok Barat. Mutu sekolah meningkat, maka secara otomatis akan menyebabkan mutu pembelajaran meningkat juga.

Jenis data penelitian ini terdiri dari data primer dan data sekunder. Menurut Riyanto (2007) data primer adalah keterangan yang diperoleh peneliti melalui penyelidikan langsung dari gejalanya atau dari sumbernya, sedangkan data sekunder adalah keterangan yang diperoleh seorang peneliti, tetapi melalui sumber lain, baik lisan maupun tulisan.

Teknik pengumpulan data menggunakan lembar observasi, wawancara, dokumentasi. Teknik analisis data menggunakan tiga alur kegiatan yaitu reduksi data, penyajian data dan penarikan kesimpulan.

\section{HASIL DAN PEMBAHASAN}

\section{Sarana Pembelajaran yang Diprioritaskan} di SMP Islam Al-Mujahidin Tempos

Dokumen program SMP Islam Al Mujahidin Tempos tahun 2019/2020, dicantumkan bahwa guru yang professional memiliki beberapa karakteristik, antara lain: (a) selalu membuat perencanaan konkrit dan detail yang siap untuk dilaksanakan dalam kegiatan pembelajaran; (b) berkehendak mengubah pola pikir lama menjadi pola pikir baru yang menempatkan siswa sebagai arsitek pembangun gagasan dan guru berfungsi untuk "melayani" dan berperan sebagai mitra siswa supaya kegiatan belajar bermakna berlangsung pada semua individu; (c) bersikap kritis dan berani menolak kehendak yang kurang edukatif; (d) berkehendak mengubah pola tindak dalam menetapkan peran siswa, peran guru dan gaya mengajar; (e) berani meyakinkan kepala Sekolah, orang tua dan masyarakat agar dapat berpihak pada mereka terhadap beberapa inovasi pendidikan yang edukatif; (f) bersikap kreatif dalam membangun dan menghasilkan karya pendidikan.

Peningkatan Mutu Sarana Pembelajaran dalam sudut pandang kepala Sekolah SMP Islam Al Mujahidin adalah Kepala Sekolah yang memiliki disiplin kerja yang tinggi dengan didukung oleh yayasan, masyarakat, guru dan semua stakeholder yang berada di sekolah tersebut., seperti yang disampaikannya sebagai berikut:

“...meningkatkan Mutu sarana pembelajaran diawali dari peningkatan disiplin kerja guru untuk meningkatkan kompetensinya. Beberapa kompetensi utama yang harus dimiliki guru, antara lain memahami landasan dan wawasan pendidikan, menguasai materi pembelajaran dan pengelolaan pembelajaran, menguasai evaluasi pembelajaran, dan memiliki kepribadian, wawasan profesi dan pengembangannya, memiliki perangkat pembelajaran serta didukung dengan sarana pembelajaran yang memadai".

Dari beberapa pendapat tersebut tentunya juga didukung oleh hasil kuesioner. Berdasarkan jawaban guru pada kuesioner yang menanyakan tentang mutu sarana pembelajaran, terdapat $83 \%$ (25 guru) yang menyatakan mutu sarana pembelajaran SMP Islam Al Mujahidin adalah baik dengan alasan sebagai berikut: (a) sarana pembelajaran memadai dengan beberapa fasilitas pembelajaran berupa LCD Proyektor, Laboraturium IPA dan Laboraturium Kamputer (b) hampir semua guru lulusan sarjana dan mengajar sesuai bidang studinya (c) dilengkapi dengan perangkat pembelajaran yang wajib dimiliki guru.

Kepala sekolah SMP Islam Al-Mujahidin Tempos juga memiliki rencana untuk mengadakan dan menambah sarana yang akan menjadi prioritas untuk mereka kembangkan. Seperti peralatan Lab bahasa, LCD dan bukubuku. Hal ini di ungkapkan oleh kepala sekolah sendiri sebagai berikut:

“.....kami disini memiliki rencana untuk menambah peralatan Leb bahasa, LCD dan buku-buku sebagai 
sarana yang di prioritaskan untuk di kembangkan dan di tingkatkan. Karena sarana tersebut dapat meningkatkan proses KBM di sekolah".

\section{Peran kepala sekolah dalam meningkatkan mutu sarana pembelajaran di sekolah SMP Islam Al Mujahidin Tempos}

Peranan kepala sekolah dalam rangka meningkatkan mutu pembelajaran sangat penting karena dapat mempengaruhi berhasil dan tidaknya mutu pendidikan itu sendiri. Secara garis besar, ruang lingkup tugas kepala sekolah dapat diklasifikasikan ke dalam dua aspek pokok, yaitu pekerjaan di bidang administrasi sekolah dan pekerjaan yang berkenaan dengan pembinaan profesional kependidikan.

Dalam bidang pendidikan, yang dimaksud dengan mutu memiliki pengertian sesuai dengan makna yang terkandung dalam siklus pembelajaran.Secara ringkas dapat disebutkan beberapa kata kunci pengertian mutu, yaitu: sesuai standar, sesuai penggunaan pasar/ pelanggan, sesuai perkembangan kebutuhan, dan sesuai lingkungan global. Adapun yang dimaksud mutu sesuai dengan standar, yaitu jika salah satu aspek dalam pengelolaan pendidikan itu sesuai dengan standar yang telah ditetapkan.

Mutu sekolah terdiri dari setiap komponen yang saling mendukung satu dengan lainnya (suatu sistem). Dengan demikian mutu sistem tergantung pada mutu komponen yang membentuk sistem, serta proses yang berlangsung hingga membuahkan hasil. (Wulandari et al, 2018) Dalam pelaksanaan manajemen peningkatan mutu, kepala sekolah harus senantiasa memahami sekolah sebagai suatu sistem organisasi (Suwardi, 2014).

Oleh karena itu, dibutuhkan beberapa strategi dalam upaya meningkatkan mutu pendidikan yang dilakukan oleh kepala sekolah. Menurut Fauzuddin (2011) ada beberapa strategi yang dilakukan kepala sekolah dalam mencapai sekolah efektif antara lain: (a) Optimalisasi proses pembelajaran; (b) Memberdayakan potensi siswa, dan (c) Menjalin kerja sama dengan berbagai pihak untuk mendukung prestasi siswa.

Sedangkan faktor-faktor pendukung dalam meningkatkan prestasi sekolah adalah: (a) Input siswa yang unggul dan terseleksi; (b) Memperoleh dukungan dari komponen sekolah; (c) Jalinan kerjasama dan kemitraan dengan orang tua, masyarakat, pemerintah, pihak swasta, dan lembaga pendidikan internasional.

Pelaksanaan manajemen peningkatan mutu, kepala sekolah harus senantiasa memahami sekolah sebagai suatu sistem organisasi. Kepala sekolah dalam membangun sumber daya manusia melalui manajemen personalia (Suwardi, 2014). Secara umum Slamet (2000) menjelaskan karakteristik kepala sekolah tangguh, yaitu: (a) Memiliki wawasan jauh kedepan dan tahu tindakan apa yang harus dilakukan serta paham benar tentang cara yang akan ditempuh; (b) Memiliki kemampuan mengkoordinasikan dan menyerasikan seluruh sumberdaya terbatas yang ada; (c) Memiliki kemampuan mengambil keputusan, memobilisasi sumberdaya yang ada, toleransi terhadap perbedaan, dan (d) Memiliki kemampuan memerangi musuh-musuh kepala sekolah, yaitu ketidakpedulian, kecurigaan, tidak membuat keputusan, mediokrasi, imitasi, arogansi, pemborosan, kaku, dan bermuka dua dalam bersikap dan bertindak.

Sarana Pembelajaran merupakan bidang yang penting dalam meningkatkan kualitas pembelajaran di sekolah. Sarana pembelajaran menjadi alat bantu untuk membantu guru dalam mengajar. Di SMP Islam Al Mujahidin Tempos, Peningkatan Mutu sarana pembelajaran ini telah dicantumkan dalam program Renstra (Rencana Strategis) Sekolah. Peningkatan mutu pembelajaran menjadi salah satu tujuan Sekolah seperti yang termuat dalam dokumen Sekolah yang tertulis bahwa ada beberapa tujuan Sekolah, antara lain: (a) Sekolah memiliki guru yang profesional dengan kualifikasi S1 dan Akta IV sesuai dengan bidang keahliannya. (b) Sekolah memiliki pendidik yang profesional dan inovatif dalam mengembangkan kemampuan pengelolaan proses pembelajaran.

Dengan memperhatikan Visi, Misi dan tujuan Sekolah, maka muncullah program-program pokok yang perlu mendapatkan prioritas. Program tersebut antara lain adalah: (a) Peningkatan mutu serana pembelajaran di sekolah; (b) Peningkatan pelaksanaan guru dalam menggunakan sarana yang ada di sekolah

Untuk mencapai tujuan Sekolah dan juga untuk menunjang berjalannya program prioritas tersebut, maka Sekolahpun menentukan strategi pelaksanaannya. Strategi tersebut seperti yang tercantum dalam dokumen antara lain adalah: (a) Peningkatan Mutu sarana pembelajaran kerja 
sama dengan pemerintah, dalam hal ini Dinas Pendidikan kabupaten dalam rangka mencapai pendidikan yang baik dan berkualitas; (b) Peningkatan pelaksanaan guru dalam menggunakan sarana pembelajaran, untuk mewujudkan tenaga pendidikan yang profesional dan berkualitas.

Peningkatan mutu sarana pembelajaran dilakukan oleh kepala sekolah agar memudahkan guru dalam melaksanakan proses kegiatan belajar mengajar di sekolah dan dengan tujuan memberikan pembinaan atau bimbingan untuk meningkatkan profesionalisme guru. Dari pernyataan tersebut dapat dikatakan bahwa peningkatan mutu sarana pembelajaran yang dilakukan oleh kepala Sekolah adalah: (a) Pengarahan dari pengawas pembina atau kepala sekolah pada saat rapat koordinasi di Sekolah, (b) Mengirim guru untuk mengikuti pelatihan dan penataran.

Menurut ketua Yayasan peran kepala sekolah SMP Islam Al-Mujahidin Tempos sudah sangat aktif dan baik. Karena peran kepala sekolah yang baik merupakan salah satu kunci antara sekolah dengan pihak yayasan secara efektif untuk menggapai misi sekolah.

Peran kepala sekolah dalam pemeliharaan sarana pembelajaran di sekolah SMP Islam Al Mujahidin Tempos.

Sarana Pembelajaran di SMP Islam Al Mujahidin Tempos pada tahun pelajaran 2019/2020 sebagaimana dijelaskan oleh Korsan Sarana Prasarana (Bapak H.Yunus, S.Pd. ) sebagai berikut:

.......Dengan kepemimpinan kepala sekolah dalam meningkatkan mutu sarana pembelajaran SMP Islam Al - Mujahidin Tempos. Guru-guru di SMP Islam Al Mujahidin Tempos merasa senang dan guru tidak segan-segan bertemu langsung dan sharing untuk mendiskusikan atau memberikan masukan kepada kepala sekolah dalam hal sarana dan prasaran akan kebutuhan sekolah dan kebutuhan guru-guru, yang bisa menunjang dalam proses pembelajaran di SMP Islam Al Mujahidin Tempos.

Kepala sekolah merupakan unsur vital bagi efektifitas lembaga pendidikan. Kepala sekolah yang baik akan bersikap dinamis untuk menyampaikan berbagi macam program pendidikan di sekolah. Keberhasilan sekolah adalah keberhasilan kepala sekolah. Kepala sekolah yang berhasil adalah apabila memahami keberadaan sekolah sebagai organisasi yang kompleks, serta mampu melaksanakan peranan dan tanggung jawab untuk memimpin sekolah.

Hal tersebut juga diperkuat oleh penjelasan Korsan kurikulum, pada saat yang sama ketika menjelaskan program Sekolah, sebagai berikut:

........Peran seorang kepala sekolah sebagai menejerial dan sebagai perencana harus mampu meningkatkan kualitas sekolah mulai dari personil, yaitu staf sampai kepada guru-guru di sekolah, seorang kepala sekolah harus mampu mengkoordinir seluruh anggota atau personil dalam sekolah, juga tentunya dalam hal sarana, yang menunjang peningkatan prestasi dan kualitas sekolah.

Dalam pandangan kepala Sekolah bahwa langkah untuk pengembangan sarana prasarana, khususnya sarana prasarana yang digunakan dalam proses belajar kelas VI disampaikan sebagai berikut:

........kami mengatur sesuai dengan kompetensi mereka seperti menangani masalah sarana, ada Korsan bagian sarana, itulah yang mengontrol semua pengadaan dan pemeliharaan jadi kalau ada kebutuhan pengadaan sarana tentu saya percayakan kepada Korsan bagian sarana. Peranan kepala sekolah dalam meningkatkan mutu sarana pembelajaran di SMP Islam Al - Mujahidin Tempos disesuaikan dengan kompetensinya.

Dalam pandangan seorang kepala sekolah itu sendiri yakni dapat bertanggung jawab terhadap peningkatan mutu sarana yang menunjang kualitas sekolah dalam proses pembelajaran, SMP Islam Al - Mujahidin Tempos saat ini memiliki beberapa sarana yang dapat menunjang pembelajaran, seperti halnya laboratorium IPA, Lab Komputer, berbagai macam media pembelajaran seperti LCD, alatalat olah raga, macam-macam buku dan masih banyak lagi lainnya. Meski beberapa sarana sudah ada yang rusak dan insya Allah akan segera diperbaharui.

SMP Islam Al - Mujahidin Tempos juga memiliki sarana olahraga untuk menunjang aktifitas dalam bidang keolahragaan juga 1 
gedung perpustakaan untuk peserta didik mencari referensi dan tempat menambah pengetahuan dari buku-buku yang ada di perpustakaan, yang Alhamdulillah sudah terbilang lengkap, dari berbagai yang dibutuhkan, baik untuk mata pelajaran umum sendiri juga yang diluar dari mata pelajaran yang ada di kelas, contohnya bacaan novelnovel islami yang akan menambah wawasan murid-murid yang suka dalam membaca. Juga sudah ada rancangan. Hal ini di ungkapakn oleh kepala perpustakaan Ibu Nurul Alperarosana sebagai berikut:

........Insya Allah tahun depan dalam kelengkapan sarana seperti laboratorium bahasa dan kelengkapan sarana yang lainnya akan di lengkapi kepala sekolah namun sekarang utntuk pengadaan buku bacaan sudah lengkap".

Berdasarkan hal tersebut kepala sekolah dalam meningkatkan mutu sarana di SMP Islam Al - Mujahidin Tempos, kepala sekolah mengelola dana dan merancang kebutuhan sarana secara terstuktur seperti berkerja sama dengan staf, memfasilitasi guru-guru dalam proses pembelajaran, sesuai dengan yang diungkapkan oleh Bendahara sekolah Nur Mewah, S.Pd sebagai berikut:

.....program rencana anggaran belanja sekolah dalam hal pembelian sarana dan peningkatan sarana pendukung pembelajaran guru juga dibuat oleh kepala sekolah, komite sekolah dan dan bendahara.

Tugas utama sebagai seorang kepala sekolah dalam administrasi menyusun daftar kebutuhan mereka akan alat-alat sarana tersebut dan mempersiapkan perkiraan tahunan untuk diusahakan penyediaannya, dalam pengadaan sarana dan prasarana memang ada dari dana BOS itulah yang bapak kelolah untuk pembangunan sarana yang dibutuhkan, beberapa juga dari sumbangsi dari donator yang dari alumni SMP Islam Al - Mujahidin Tempos itu sendiri, untuk hal itu kepala sekolah menunjuk seorang staf yang menangani hal tersebut dalam hal pengurusan sarana.

\section{KESIMPULAN}

Kesimpulan berisi rangkuman singkat atas hasil penelitian dan pembahasan. [Times New Roman, 12, normal].

Peran kepala sekolah dalam meningkatkan mutu sarana di SMP Islam Al - Mujahidin Tempos sudah lumayan membantu dalam proses pembelajaran, walaupun masih belum maksimal dengan pengadaan sarana yang dibutuhkan, namun kepala sekolah sebagai administrator sudah melakukan tugas dan fungsinya dengan baik seperti berikut ini:

1. Memperhatikan kebutuhan-kebutuhan sarana guru-guru dalam proses pembelajaran.

2. Pendekatan yang di lakukan oleh kepala sekolah, guru-guru tidak merasa segan untuk menyampaikan saran dan berbicara langsung dengan kepala sekolah mengenai kebutuhan dalam proses pembelajaran.

3. Kepala sekolah terjun langsung dalam pengontrolan pembangunan prasarana sekolah bersama dengan wakil kepala sekolah beserta koordinator bidang sarana dan prasarana.

\section{SARAN}

1. Peran kepala sekolah di SMP Islam AlMujahidin Tempos sebaiknya terlebih dahulu menentukan teknik-teknik dan arah tujuan dalam meningkatkan peran kepemimpinan tersebut. Sehingga apa yang laksanakan akan tercapai sesuai dengan yang diharapkan.

2. Dalam melaksanakan tugas kepemimpinan kepala sekolah di SMP Islam Al-Mujahidin Tempos untuk meningkatkan mutu sarana pembelajaran harus menentukan teknik dan arah tujuan serta memperhatikan sarana dan pendidikan guru serta memberikan pelatihan-pelatihan kepada guru dalam meningkatkan kompetensi pendidik, sehingga akan menghasilkan dan meningkatkan mutu pembelajaran yang baik dan berkompeten.

3. Program-program harus disusun secara baik, jelas dan terarah, sehingga dalam proses pelaksanaannya dapat dilakukan dengan mudah dan baik. 


\section{DAFTAR PUSTAKA}

Afework, T. H., \& Asfaw, M. B. (2014). The availability of school facilities and their effects on the quality of education in government primary schools of Harari Regional State and East Hararghe Zone, Ethiopia. Middle Eastern \& African Journal of Educational Research, 11, 5971.

Arikunto, S. (2013). Prosedur Penelitian Suatu Pendekatan Praktik. Jakarta: PT Rineka Cipta.

Bachri, T. S. (2016). The effect of school supervisors competence and school principals compotence on work motivation and performance of junior high school teachers in maros regency, Indonesia. International Journal Of Envirimental Dan Science Education, 11(15), 7310-7317.

Creswell, J. W. (2015). Penelitian Kualitatif \& Desain Riset: Memilih diantara Lima Pendekatan (3rd Editio). Yogyakarta: Pustaka Pelajar.

Fauzuddin. (2011). Kepemimpinan Transformasional Kepala Sekolah. Disertasi. Program Pascasarjana universitas Negeri Malang. Tidak dipublikasikan.

Fitrah, M. (2017). Peran kepala sekolah dalam meningkatkan mutu pendidikan. Jurnal Penjaminan Mutu, 3(1), 31-42

Hadisaputra, S., Gunawan, G. \& Yustiqvar, M. (2019). Effects of Green Chemistry Based Interactive Multimedia on the Students' Learning Outcomes and Scientific Literacy. Journal of Advanced Research in Dynamical and Control Systems, 11(7), 664-674

Juliantoro, M. (2017). Peran Kepala Sekolah dalam Meningkatkan Mutu Pendidikan. Jurnal Al-Hikmah, 5(2), 24-38.

Muflihah, A., \& Haqiqi, A. K. (2019). Peran Kepala Sekolah Dalam Meningkatkan Manajemen Mutu Pendidikan Di Madrasah Ibtidaiyah. Quality, 7(2), 48-63.

Mulyasa. E. (2004). Manajemen Berbasis Sekolah. Bandung: Remaja Rosdakarya.

Ningrum, E. S., \& Sobri, A. Y. (2015). Implementasi Kurikulum 2013 di Sekolah Dasar. Jurnal Manajemen Pendidikan, 24(5), 416-423.
Pettifor, A. E., Levandowski, B. A., MacPhail, C., Padian, N. S., Cohen, M. S., \& Rees, H. V. (2008.) Keep them in school: the importance of education as a protective factor against HIV infection among young South African women. International journal of epidemiology, 37(6), 1266-1273.

Prawirosentono S. (2007). Filosofi Baru Tentang Manajemen Mutu Terpadu Abad 21 "Kiat Membangun Bisnis Kompetitif. Jakarta : Bumi Aksara.

Purwanto. M \& Ngalim. (2006). Administrasi dan Supervisi Pendidikan. Bandung: Remaja Rosdakarya.

Riyanto, Y. (2007). Metodologi Penelitian Pendidikan (Kualitatif dan Kuantitatif). Surabaya: Unesa Universty Press.

Sallis, E. (2002). Total Quality Management in Education. New York: Psychology Press.

Slamet, P.H. (2001). Manajemen Berbasis Sekolah. Jurnal Pendidikan dan Kebudayaan. 27.

Sugiyono. (2013). Metode Penelitian Kuantitatif, Kualitatif Dan R\&D. Bandung: Alfabeta.

Sunarijah, S. (2018). Upaya Meningkatkan Mutu Sekolah Dasar Menghadapi Era Revolusi Industri 4.0. Ta'dibia: Jurnal Ilmiah Pendidikan Agama Islam, 8(2), 1526.

Suwardi, S. (2014). Kepemimpinan Kepala Sekolah Dalam Pengembangan Lembaga Pendidikan Islam Kreatif SD Muhammadiyah Kota Madiun. Jurnal Manajemen Pendidikan, 9(2), 186-195.

Uline, C., \& Tschannen-Moran, M. (2008). The walls speak: The interplay of quality facilities, school climate, and student achievement. Journal of educational administration.

Wahjosumidjo. (2002). Kepemimpinan Kepala Sekolah Tinjauan Teoritik dan Permasalahannya. Jakarta: PT. Raja Grafindo Persada.

Wulandari, Y., Sartika, E. D., \& Perawati, P. (2018). Strategi Kepala Sekolah Perempuan Dalam Meningkatkan Mutu Pendidikan. JMKSP (Jurnal Manajemen, Kepemimpinan, dan Supervisi Pendidikan), 3(1). 
Yustiqvar, M., Gunawan, G., \& Hadisaputra, S. (2019). Green Chemistry Based Interactive Multimedia on Acid-Base Concept. In Journal of Physics: Conference Series (Vol. 1364, No. 1, p. 012006). IOP Publishing. 